\title{
STRATEGI KOMUNIKASI PEMASARAN USAHA SKALA MIKRO (MICRO ENTERPRISE) KUB BAJRAH GUNAH KLAMPIS BANGKALAN PADA PRODUK TERASI, PETIS DAN KERUPUK IKAN
}

\author{
Dwi Ratna Hidayati \\ Program Studi Agribisnis Fakultas Pertanian Universitas Trunojoyo Madura \\ nonratna1@gmail.com
}

\begin{abstract}
ABSTRAK
Potensi lestari sumber daya ikan (SDI) laut Indonesia sekitar 6,4 juta ton per tahun. Seiring dengan hal tersebut, potensi bahan baku perikanan yang sedemikian besar mendorong tumbuhnya usaha-usaha pengolahan makanan berbahan dasar ikan terutama usaha skala mikro kecil menengah, khususnya di wilayah-wilayah sentra penghasil perikanan seperti di kecamatan Klampis. Salah satu Kelompok Usaha Bersama (KUB) skala mikro yang mengusahakan produk berbasis hasil perikanan adalah KUB "Bajrah Gunah" yang berlokasi di Kecamatan Klampis Kabupaten Bangkalan yang memproduksi petis, terasi dan kerupuk ikan. Namun demikian,usaha skala mikro (micro enterprise) seringkali terkendala berbagai permasalahan terutama dibidang pemasaran, apalagi dalam kondisi harus bersaing dengan perusahaan skala menengah ataupun industri skala besar lainnya. Komunikasi pemasaran merupakan kata kunci strategis untuk memainkan peran produk lokal agar bisa berkembang oleh karena itu penelitian ini dilakukan untuk mengetahui strategi komunikasi pemasaran yang dilakukan oleh usaha skala mikro KUB Bajrah Gunah. Metode analisis yang digunakan adalah SWOT analysis yang datanya diperoleh hasil Focus Group Discussion. Hasil penelitian menunjukkan bahwa strategi komunikasi pemasaran yang harus dilakukan adalah perbaikan label sebagai sarana komunikasi dan promosi terhadap pelanggan, Perluasan jejaring, model serta saluran komunikasi pemasaran untuk membidik target konsumen yang lebih luas melalui penambahan media komunikasi pemasaran selain handphone, seperti web dan blog, serta pembuatan sarana promosi lainnya seperti leaflet, banner serta ikut serta dalam jejaring pameran yang lebih luas, branding yang kuat dengan label yang lebih marketable, perbaikan kemasan yang sesuai bagi seluruh produk yang ada, pelatihan secara kontinu serta berjenjang dari pihak terkait serta plang papan nama KUB di dekat jalan utama untuk menginformasikan keberadaaan KUB Bajrah Gunah.
\end{abstract}

Kata kunci: Komunikasi, Pemasaran, Micro enterprise, KUB Bejrah Gunah

\author{
MARKETING COMMUNICATION STRATEGY OF MICRO ENTERPRISE \\ KUB BEJRAH GUNAH KLAMPIS BANGKALAN \\ ON TERASI, PETIS AND FISH CHIPS
}

\begin{abstract}
Fish potency of Indonesian sea reachs about 6,4 millions tonne per year. As this situation, material potential for fish base has encouraged establishment of food processing business by fish base especially small medium or micro scale business in central area of fish such as in Klampis sub district. One of micro enterprise producing fish base product is KUB "Bajrah Gunah" located in Klampis sub district of Bangkalan district. This business produces petis (fermented
\end{abstract}




\section{Agriekonomika, ISSN 2301-9948

shrimp), terasi (shrimp condiment) and fish chips. Nevertheless, microenterprise oftentimes face problems due to marketing, especially in competing with other industrial both middle or big scale. Marketing communication is strategic keywords in playing role for local product to grow. Therefore this research is aimed to formulate communication strategy for microenterprise Bejrah Gunah Analysis method being used was SWOT analysis which is supported by data from Focus Group Discussion. Research result showed that marketing communication strategy that should be done is by improvement of label as communication media as well as promotion to customer, exploration of network, model as well as communication channel to target wider consumer through addition of communication media other than handphone, such as web and blog, creation of other promotion media such as leflet, banner and joining more exhibition, strong marketable branding, packaging improvement, training from related official agencies and signboard name installation near main road to inform business existency.

Keywords: Marketing, Communication, Micro Enterprise, KUB Bejrah Gunah

\section{PENDAHULUAN}

Potensi lestari sumber daya ikan (SDI) laut Indonesia sekitar 6,4 juta ton per tahun. Total produksi perikanan Indonesia tahun 2014 berdasarkan data dari Kementerian Kelautan (2014), mencapai total 14.521.349 ton. Provinsi Jawa Timur memberikan kontribusi terhadap sektor perikanan nasional sebesar 7.17 persen, dan salah satu Kabupaten yang menjadi penghasil produk perikanan adalah Kabupaten Bangkalan. Berdasarkan data BPS Jatim Tahun 2014, potensi perikanan baik laut maupun darat di Kabupaten Bangkalan cukup besar yaitu sekitar 118.609 ton pada tahun 2013.

Daerah penghasil terbesar perikanan adalah Kecamatan Klampis, Sepulu, Tanjung Bumi dan Kwanyar. Seiring dengan hal tersebut, potensi bahan baku perikanan yang sedemikian besar mendorong tumbuhnya usaha-usaha pengolahan makanan berbahan dasar ikan terutama usaha skala mikro kecil menengah, khususnya di wilayah-wilayah sentra penghasil perikanan seperti di kecamatan Klampis. Salah satu Kelompok Usaha Bersama (KUB) skala mikro yang mengusahakan produk berbasis hasil perikanan adalah KUB "Bajrah Gunah" yang berlokasi di Kecamatan Klampis Kabupaten Bangkalan. KUB ini berdiri pada tahun 2009 dan memproduksi petis, terasi dan kerupuk ikan.

Micro enterprise secara umum biasanya merupakan bisnis keluarga atau orang yang mempekerjakan dirinya sendiri dalam sektor semi-formal dan informal, yang mana kebanyakan memiliki kesempatan sangat kecil untuk berkembang menjadi perusahaan besar, sulit mengakses keuangan perbankan bahkan sulit bersaing secara internasional. Bahkan pada beberapa Negara dikuasi oleh etnis tertentu seperti Indoneisa-Pribumi dan indigenous di Bolivia (Hallberg-World Bank, 1994). Dari World Bank juga menyatakan bahwa UKM Mikro atau micro enterprise adalah para UKM dengan kemampuan sifat pengrajin namun tidak memiliki jiwa kewirausahaan dalam mengembangkan usahanya

Namun demikian,usaha skala mikro seringkali terkendala berbagai permasalahan terutama dibidang pemasaran, apalagi dalam kondisi harus bersaing dengan perusahaan skala menengah ataupun indusri skala besar lainnya. O'broin (2013), menyatakan bahwa diperkirakan sekitar 70\% bisnis kecil mengalami kebangkrutan setelah 5 tahun berjalan. Persentase yang sedemikian besar disebabkan oleh strategi komunikasi pemasaran yang buruk. 
SMME Desk of Durban Chamber of Commerece (2009), menyatakan bahwa $90 \%$ bisnis skala mikro tidak bisa bertahan dalam lima tahun pertama bukan karena produknya tetapi karena tidak mampu membangun tempat dalam pasar. Van Scheers dan Radipere (2008), menambahkan bahwa komunikasi pemasaran adalah bantuan utama bagi usaha skala mikro untuk membedakan diri dari para pesaing. Kegiatan promosi yang dilakukan oleh UMKM masih terkendala biaya sehingga hanya beberapa unsure komunikasi dalam pemasaran terpadu yang dapat diterapka UMKM yaitu: iklan, publisitas, promosi penjualan dan pemasaran langsung. Dengan dana terbatas, UMKM dapat menggunakan kegiatan promosi antara lain penyebaran brosur, pemasangan banner, pemberian diskon atau contoh prosuk secara gratis serta pemasaran online menggunakan internet (Chrismardani, 2014).

Secara umum, ketika mengamati bentuk-bentuk komunikasi pemasaran yang dilakukan perusahaan berskala kecil dan menengah, keterbatasan dana tetap terlihat. Perusahaan-perusahaan itu tetap saja tidak dapat secara maksimal melakukan komunikasi pemasaran akibat keterbatasan dana. Hal ini membuat mereka cenderung memanfaatkan hal-hal yang mampu mereka lakukan seperti pemberian diskon, iklan baris, ataupun undangan publikasi melalui radio (Isnaini, 2010). Serupa dengan Etaswara dalam Hidayat (2011), menyatakan bahwa pemasaran era informasi adalah komunikasi dan komunikasi adalah pemasaran dimana keduanya tidak dapat dipisahkan. Oleh karenanya perlu ada role model perumuan strategi komunikasi pemasaran yang diperlukan bagi usaha skala mikro untuk membantu pengembangan bagi usaha skala mikro (micro enterprise) tersebut. Berdasarkan latar belakang tersebut, maka penelitian ini mencoba merumuskan strategi komunikasi pemasaran yang tepat bagi Usaha Skala Mikro seperti KUB Bejrah Gunah.

\section{METODE PENELITIAN}

Lokasi penelitian ditentukan secara sengaja (purposive) di Kelompok Usaha Bersama (KUB) Bajrah Gunah sebagai salah satu usaha skala mikro yang yang terletak di Desa Sepao Kecamatan Klampis Kabupaten Bangkalan. Anggota KUB Bajrah Gunah berjumlah 17 orang yang saling terkait sebagai saudara atau tetangga dan semuanya dijadikan sebagai responden. Data yang digunakan adalah data primer dan sekunder. Data primer diperoleh dengan pengamatan, kuisioner, dan wawancara. Data sekunder diperoleh dari kantor desa Klampis Timur, dokumen Dinas Kelautan dan Perikanan, buku-buku referensi terkait komunikasi pemasaran dan internet.

Selanjutnya, perumusan strategi dilakukan dengan menggunakan SWOT analisis. Penentuan strategi dan taktik tersebut dibuat dalam matriks seperti pada Tabel 1. 


\section{\begin{tabular}{l|l} 
& Agriekonomika, ISSN 2301-9948 \\
April, 2016 & e ISSN 2407-6260
\end{tabular} \\ Volume 5, Nomor 1}

Tabel 1

Matrik Analisis SWOT

\begin{tabular}{|c|c|c|}
\hline $\begin{array}{c}\text { Faktor } \\
\text { Eksternal } \\
\text { Faktor } \\
\text { Internal }\end{array}$ & $\begin{array}{c}\text { Strength } \\
\text { (Kekuatan) }\end{array}$ & $\begin{array}{c}\text { Weakness } \\
\text { (Kelemahan) }\end{array}$ \\
\hline Opportunity & Strategi SO & Strategi WO \\
\hline (Peluang) & $\begin{array}{l}\text { Ciptakan strategi yang } \\
\text { menggunakan kekuatan untuk } \\
\text { memanfaatkan peluang }\end{array}$ & $\begin{array}{l}\text { Ciptakan strategi yang } \\
\text { meminimalkan kelemahan } \\
\text { untuk memanfaatkan } \\
\text { peluang }\end{array}$ \\
\hline $\begin{array}{l}\text { Threatment } \\
\text { (Ancaman) }\end{array}$ & $\begin{array}{l}\text { Strategi ST } \\
\text { Ciptakan strategi yang } \\
\text { menggunakan kekuatan untuk } \\
\text { mengatasi ancaman }\end{array}$ & $\begin{array}{l}\text { Strategi WT } \\
\text { Ciptakan strategi } \\
\text { meminimalkan kelemahan } \\
\text { untuk menghindari ancaman }\end{array}$ \\
\hline
\end{tabular}

Sumber: Data Primer Diolah, 2015

Menurut David (2006), Semua organisasi memiliki kekuatan dan kelemahan dalam area fungsional bisnis. Tidak ada perusahaan yang sama kuatnya atau lemahnya dalam semua area bisnis. Kekuatan atau kelemahan internal, digabungkan dengan peluang atau ancaman dari eksternal dan pernyataan misi yang jelas, menjadi dasar untuk penetapan tujuan dan strategi. Tujuan dan strategi ditetapkan dengan maksud memanfaatkan kekuatan internal dan mengatasi kelemahan. Rangkuti (2006), berikut ini adalah keterangan dari matriks SWOT diatas :

1. Strategi SO (Strength and Oppurtunity). Strategi ini dibuat berdasarkan jalan pikiran perusahaan, yaitu dengan memanfaatkan seluruh kekuatan untuk merebut dan memanfaatkan peluang sebesar - besarnya.

2. Strategi ST (Strength and Threats). Strategi dalam menggunakan kekuatan yang dimiliki perusahaan untuk mengatasi ancaman.

3. Strategi WO (Weakness and Opportunity). Strategi ini diterapkan berdasarkan pemanfaatan peluang yang ada dengan cara meminimalkan kelemahan yang ada.

4. Strategi WT (Weakness and Threats). Strategi ini berdasarkan kegiatan yang bersifat defensif dan berusaha meminimalkan kelemahan yang ada serta menghindari ancaman.

\section{HASIL DAN PEMBAHASAN}

Kondisi Usaha Bisnis Skala Mikro KUB Bejrah Gunah dan Pemasarannya

Kelompok Usaha Bajrah Gunah secara legal terdaftar di Dinas Kelautan dan Perikanan Kabupaten Bangkalan pada tanggal 29 September 2009 dalam bentuk Kelompok Pengolah dan Pemasar (POKHLASAR) yang beralamat di Dusun Sepao Desa Klampis Kecamatan Klampis. Kelompok ini merupakan usaha bersama dengan jumlah anggota 17 orang yang menghasilkan petis ikan, terasi udang dan kerupuk, namun dalam perkembangannya juga mulai memproduksi ikan kering, dan makanan. Anggota tersebut terbagi ke dalam kelompok-kelompok kecil yang memproduksi petis sebanyak 4 orang, terasi udang 3 orang, dan kerupuk dan keripik 3 orang, dalam perkembangannya juga memperoduksi ikan kering 3 orang dan makanan 4 orang. Kelompok ini dipimpin oleh Pak Rosid dan anggota didominasi oleh unsur keluarga terdiri dari suami, 
istri, anak, adik kakak, sepupu dan beberapa lainnya tetangga. Hal ini sebagaimana disampaikan Hallberg-World Bank (1994), bahwa Micro enterprise secara umum biasanya merupakan bisnis keluarga atau orang yang mempekerjakan dirinya sendiri dalam sektor semi-formal dan informal, yang mana kebanyakan memiliki kesempatan sangat kecil untuk berkembang menjadi perusahaan besar, sulit mengakses keuangan perbankan bahkan sulit bersaing secara internasional.

Secara geografis, lokasi ini persis berada di pinggir pantai dan berlimpah produksi ikan. Hal ini menjadikan nilai positif KUB Bajrah dengan menggunakan sumber daya lokal untuk mengembangkan produk. Di sisi lain, adanya KUB ini menambah jiwa kewirausahaan penduduk sekitar. Kelompok Usaha Bersama ini dibangun atas dasar kedekatan hubungan keluarga ataupun lokasi tempat tinggal. Sebagaimana Kadin pada tahun 2008 meyatakan bahwa permasalahan utama yang dihadapi UMKM adalah permasalahan keterbatasan modal baik modal kerja maupun investasi dan kesulitan pemasaran oleh karenanya tujuan utama didirikannya KUB Bajrah adalah untuk saling bantu membantu antar pengusaha skala mikro agar lebih berkembang.

Pada bulan Oktober 2014, KUB Bajrah Gunah ini sudah masuk ke kantor merk dagang dan telah memiliki etiket merk. Pendaftaran etiket merk menunjukkan upaya pemberian adding value terhadap produk yang dihasilkan. Merk sebagai lambang produk yang dijual serta sebagai salah satu penempatan posisi tawar atas produk pesaing. Penetapan merk memberikan kekuatan terhadap suatu produk dan sebagai pembeda antarproduk. Wilayah pemasaran meliputi Kalimantan, Pasuruan, Bawean dan Malaysia melalui koneksi pribadi/relasi. Sistem yang dijalankan oleh Kelompok Usaha bersama (KUB) Bajrah Gunah ini adalah kelompok usaha bersama dimana para anggota memproduksi produk dan pemasaran dibantu oleh ketua KUB dengan mengemas ulang produk untuk dipasarkan.

\section{Strategi Komunikasi Pemasaran KUB Bejrah Gunah}

Eksistensi pasar bebas di lingkup ASEAN dapat menjadi ancaman bagi pelaku Koperasi dan UMKM yang tidak mampu beradaptasi dan meningkatkan keunggulan kompetitifnya. Oleh karenanya hal ini menjadi tantangan untuk meningkatkan daya saing UMKM, dari sisi kelembagaan maupun dari sisi produk yang dihasilkan. Struktur pelaku usaha hingga saat ini didominasi usaha mikro yang informal. Para pelaku usaha ini memiliki aset, kualitas SDM, akses ke pembiayaan dan produktivitas yang sangat terbatas. Oleh karenanya terkait peningkatkan kemampuan dan daya saing, UMKM harus berpacu dalam beberapa hal yakni peningkatan SDM yang kompeten/human capital, meningkatkan kualitas produk, melakukan efisiensi usaha, meningkatkan kemitraan usaha dan membangun jejaring komunikasi pemasaran yang kuat.

Peran penting pemerintah lebih diarahkan untuk memfasilitiasi beberapa hal antara lain perijinan, fasilitasi akses bahan baku, teknologi dan informasi, bantuan teknis berupa pelatihan, pendampingan, advokasi, sekaligus menciptakan iklim yang kondusif serta fasilitasi permodalan. Pemerintah perlu terlibat aktif dalam membantu usaha kecil yang ada dimasyarakat sebagaimana hasil penelitian bahwa Muchtar dkk (2013) menyatakan bahwa kerjasama pemerintah daerah dengan swasta dalam pelaksanaan program pembangunan pedesaan melalui pola kemitraan pemerintah swasta sebagai semangat dan inovasi baru dalam mewujudkan kesejahteraan masyarakat di kabupaten Kolaka. 


\section{Agriekonomika, ISSN 2301-9948

Komunikasi pemasaran usaha skala mikro KUB Bajrah Gunah dalam memasarkan produknya yakni petis ikan dan terasi udang melalui Promosi Penjualan, Acara dan Pengalaman, Pemasaran Langsung, Pemasaran dari mulut kemulut. Alat komunikasi adalah handphone (HP) serta mengandalkan relasi meskipun jangkauan pemasaran sudah ke luar negeri yakni Malysia. Keterbatasan dana dalam komunikasi pemasaran menyebabkan usaha-usaha dari kalangan UKM sering kali mengalami hambatan dalam menjangkau konsumen yang lebih luas, seperti halnya yang mampu dilakukan oleh perusahaan berskala besar Perusahaan berskala kecil menggunakan komunikasi pemasaran yang masih sagat sederhana melalui komunikasi pemasaran mulut ke mulut atau lebih sering dikenal degan istilah 'getok tular'. Pada tataran usaha skala mikro, komunikasi pemasaran yang dilakukan KUB Bajrah Gunah secara terpusat melalui Pak Rosid selaku Ketua yang dilakukan dengan Hand Phone (HP) dan melalui relasi saudara atau pertemanan. Produk dibeli oleh ketua untuk selanjutnya dikemas dan diberi label dan dijual kembali. Peran ketua KUB Bajrah Gunah sangat besar terkait komunikasi pemasaran terutama berkaitan dengan jejaring yang dimiliki.

Secara ringkas, hasil Focus Group Discussion (FGD) menyimpulkan beberapa hal terkait lembaga Kelompok Usaha Bersama (KUB) Bajrah Gunah, serta komunikasi pemasaran yang perlu diperbaiki secara serius karena menjadi penentu utama pemasaran yang dikenal luas oleh publik. Secara detail hasil GD dituangkan dalam bentuk analisa SWOT yang medeteksi adanya kekuatan, kelemahan, Peluang dan Ancaman pada Lampiran 1.

Secara umum KUB Bejrah Gunah masih memerlukan perbaikan dalam hal komunikasi pemasaran. Hal ini dimulai dari perbaikan kemasan, brand maupun label yang menyatu dengan perbaikan pada packaging. Kekuatan utama KUB Bejrah Gunah adalah adanya jejaring melalui koneksi relasi maupun saudara serta sudah terdaftar di Dinas Kelautan dan Perikanan sebagai Pokhlasar (kelompok Pengolahan dan Pemasaran), sering memperoleh pendampingan dari dinas terkait serta lokasi yang dekat dengan jalur utama jalan raya. Kelemahan yang dimiliki adalah kemasan yang kurang menarik, label yang terlalu sederhana, adanya anggota yang rawan kepentingan sarana komunikasi yang terbatas pada handphone, lokasi yang sulit diakses.

Namun demikiaan, KUB Bejrah Gunah juga cukup memiliki peluang yang cukup besar mengingat produk ini merupakan produk khas Madura untuk oleholeh, dasar bahan baku yang melimpah karena berada di daerah pesisir, serta masih memperoleh perhatian dari pihak dinas ataupun pemerintah seperti Dinas Kelautan dan perikanan dan Pertamina WMO. Disisi lain, fasilitas komunikasi sebenarnya terbuka luas untuk pemanfaatan internet sebagai alternatif media.

Beberapa ancaman yang teridentifikasi antara lain adanya beberapa pengusaha yang membuat produk sama persis sehingga konsumen sulit membedakan produksi KUB bejrah Gunah dengan produksi dari kelompok lain, selain itu bahan baku masih tergantung pada musim ikan atau udang sehingga konsistensi bahan baku sulit diterapkan. Ancaman lain juga muncul dari pengusaha besar yang berada di wilayah lain yang sudah memiliki jaringan serta komunikasi pemasaran yang lebih baik.

Dari berbagai identifikasi dan temuan, temuan yang utama adalah bahwa jejaring dari kalangan teman ataupun saudara maupun kenalan membuat usaha skala mikro tidak terlalu memperhatikan komunikasi pemasaran secara massa. Dengan demikian, maka dapat digaris bawahi berdasarkan kekuatan, 
kelemahan, peluang dan ancaman maka perumusan strategi komunikasi pemasaran KUB Bejrah Gunah meliputi STRATEGI SO (Strength dan Opportunity) antara lain: (1) Perbaikan label yang sesuai kaidah labelling sebagai sarana promosi dan komunikasi dengan pelanggan, (2) Perluasan jejaring melalui penambahan media komunikasi pemasaran selain handphone, seperti web dan blog, serta pembuatan sarana promosi lainnya seperti leaflet, banner serta ikut serta dalam jejaring pameran yang lebih luas (3) Legalitas tidak hanya pada pendataran pokhlasar tetapi juga mengarah pada PIRT.

Sedangkan pada STRATEGI ST (Strength dan Threats) antara lain: (1) Branding yang kuat dengan label yang lebih marketable untuk menghadapi pesaing baik skala lokal maupun internasional (2) Memperluas jaringan mitra bahan baku dari wilayah lain agar pasokan berjalan secara stabil. Selanjutnya STRATEGI WO (Weanesses dan Threats) antara lain: (1) Perbaikan kemasan yang sesuai bagi seluruh produk yang ada, lebih marketable dan label yang lebih eye ctaching bagi target konsumen, (2) Mengambil mitra strategis untuk bahan baku agar pasokan berjalan secara stabil , (3) Adanya aturan yang jelas dalam kelompok baik dari sisi produksi dan pemasaran sehingga antar anggota saling tahu dan paham peran, posisi maupun kinerja KUB, (4) Pelatihan secara kontinu serta berjenjang dari pihak terkait, dan pencatatan hasil pendampingan di pihak KUB agar tidak tumpang tindih antar dinas yang satu dengan dinas yang lain.

Strategi yang terakhir adalah STRATEGI WT (weaknesses dan threats) antara lain: (1) Pembuatan aturan bagi anggota KUB Bajrah Gunah untuk memperjelas peran dan fungsi koordinasi dalam kinerja sehingga mengurangi konflik (2) Menaruh Plang papan nama KUB di dekat jalan utama untuk menginformasikan keberadaaan KUB Bajrah Gunah (3) Memperluas model dan saluran komunikasi pemasaran untuk membidik target konsumen yang lebih luas.

\section{PENUTUP}

Strategi komunikasi pemasaran yang tepat diterapkan usaha skala mikro (micro enterprise) KUB Bajrah Gunah dalam menghadapi Masyarakat Ekononomi Asean (MEA) adalah strategi terkait kondisi ideal, yakni pada strategi SO memuat: perbaikan label yang sesuai kaidah labelling sebagai sarana promosi dan komunikasi dengan pelanggan, perluasan jejaring melalui penambahan media komunikasi pemasaran selain handphone, seperti web dan blog, serta pembuatan sarana promosi lainnya seperti leaflet, banner serta ikut serta dalam jejaring pameran yang lebih luas, legalitas tidak hanya pada pendataran pokhlasar tetapi juga mengarah pada PIRT selanjutnya strategi ST antara lain: branding yang kuat dengan label yang lebih marketable untuk menghadapi pesaing baik skala lokal maupun internasional, memperluas jaringan mitra bahan baku dari wilayah lain agar pasokan berjalan secara stabil. Pada strategi WO antara lain: perbaikan kemasan yang sesuai bagi seluruh produk yang ada, lebih marketable dan label yang lebih eye catching bagi target konsumen, mengambil mitra strategis untuk bahan baku agar pasokan berjalan secara stabil, adanya aturan yang jelas dalam kelompok baik dari sisi produksi dan pemasaran sehingga antar anggota saling tahu dan paham peran, posisi maupun kinerja KUB, pelatihan secara kontinu serta berjenjang dari pihak terkait, dan pencatatan hasil pendampingan di pihak KUB agar tidak tumpang tindih antar dinas yang satu dengan dinas yang lain. Strategi WT memuat: pembuatan aturan bagi anggota KUB Bajrah Gunah untuk memperjelas peran dan fungsi koordinasi dalam kinerja sehingga mengurangi konflik, menaruh Plang papan 
nama KUB di dekat jalan utama untuk menginformasikan keberadaaan KUB Bajrah Gunah, memperluas model dan saluran komunikasi pemasaran untuk membidik target konsumen yang lebih luas.

\section{DAFTAR PUSTAKA}

Chrismardani, Yustina. 2014. Komunikasi Pemasaran Terpadu: Implementasi untuk UMKM. Jurnal NeO-Bis 8(2): 179-189.

David, Fred R. 2006. Manajemen Strategis. Edisi Sepuluh. Penerbit Salemba Empat. Jakarta.

Durban Chamber of Commerce. 2009. Chamber-BATSA Relationship. http://www.durbanchamber.co.za/site/smme-desk. Accessed in 27 Juni 2015.

Hallberg, Kristi. 1994. A Market Oriented Strategy For Small and Medium-Scale Enterprises. Washington DC. International Finance Corporation-World Bank.

Hidayat, Rahmad. Issa Dyah dan Romadhani, Sari. 2011. Pengembangan Strategi Komunikasi Pemasaran Industri Kecil Menengah (IKM). Journal of Strategic Communication 1(2): 205-221.

Muchtar, La Ode M. Prajarto N dan Subejo. 2013. Model Kemitraan Pembangunan Pedesaan di Kabupaten Kolaka Provinsi Sulawesi Tenggara. Agriekonomika 2(1): 27-39.

O'broin, Ruadhiri. 2013. The Application of Integrated Marketing Communication by Micro Business in The Republic of Ireland. Dissertation. Business Administration of Dublin School.

Isnaini, Santi. 2010. Implementasi Komunikasi Pemasaran Terpadu sebagai Penyampai Pesan Promosi Usaha Kecil Menengah (UKM) di Indonesia. JURNAL MASYARAKAT KEBUDAYAAN DAN POLITIK 22(4): 324-332 .

Van Scheers, L \& Radipere, S.(2008). Gathering Perceptions of Soweto Small Business Owners on Advertising in black townships in South Africa. Journal of Global Business Advancement 1(4): 445-458. 


\section{Lampiran 1. Diagram Matrik Strategi SWOT KUB Bajrah Guna Klampis}

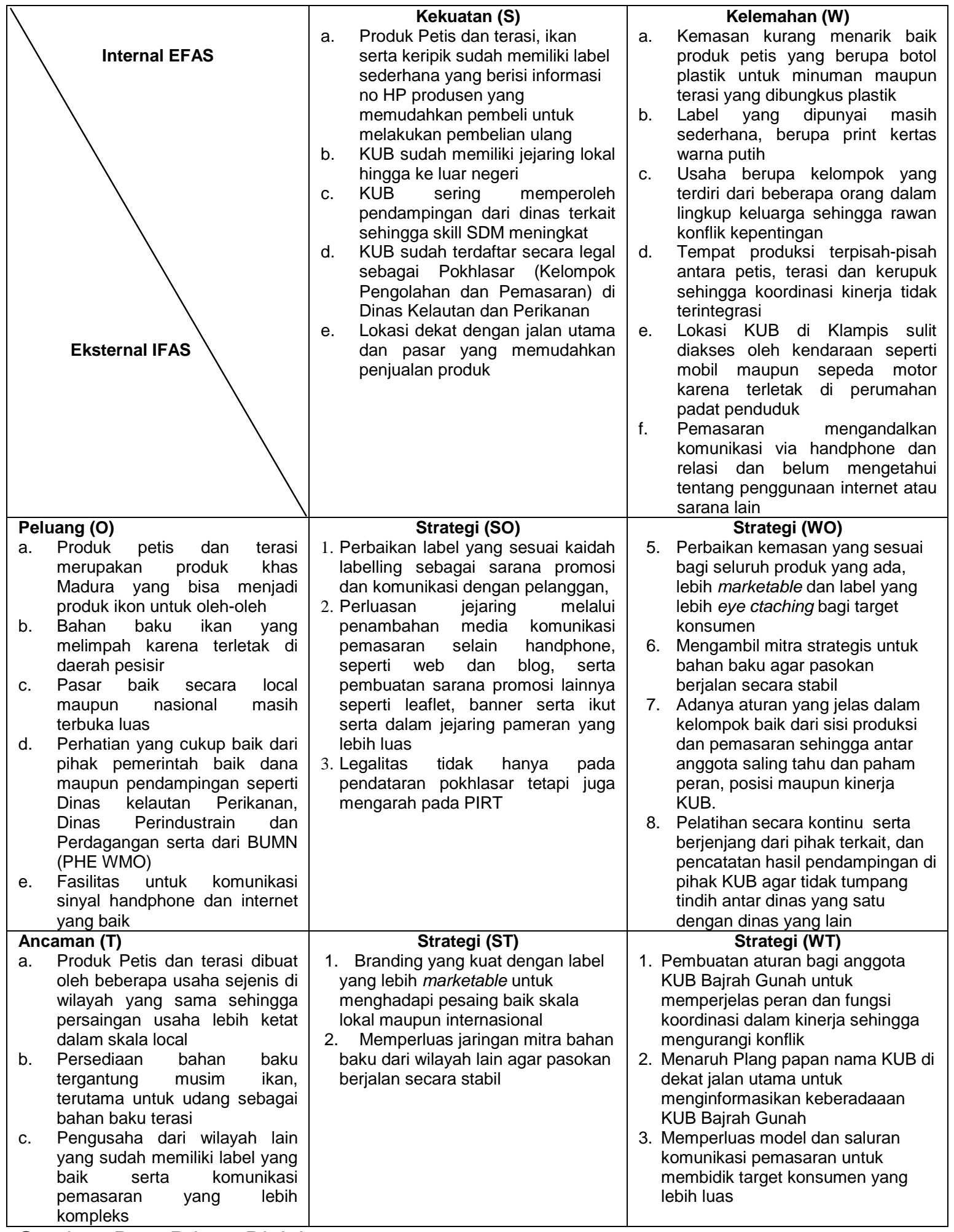

Sumber: Data Primer Diolah, 2015 